\title{
Opinión de los miembros de la Justicia Nacional en lo Penal y Civil (Familia) en situaciones de limitación del soporte vital en pediatría Opinions of members of the National Civil (Family Proceedings) and Criminal Courts in withholding or withdrawing of life support situations in pediatrics
}

\author{
Dr. Jorge O. Selandari , Dra. María S. Ciruzzi ${ }^{a}$ Dr. Adriel J. Roitman ${ }^{b}$, \\ Dra. Fernanda Ledesma ${ }^{a}$ Dra. Célica Menéndez y Dr. Hernán O. García
}

\section{RESUMEN}

Introducción. La posibilidad de sostener artificialmente las funciones vitales hace más difícil diferenciar al paciente en agonía terminal del paciente con posibilidades de supervivencia, lo que pone al grupo que lo rodea frente a un dilema. Por un lado, se presenta la continuación de soporte que solo prolongue un proceso irreversible, que causa daños físicos, psíquicos y a su dignidad. Por otro, la abstención o retiro de soporte vital sin la reflexión y el esfuerzo diagnóstico-terapéutico apropiado puede dejar sin esperanza y llevar a la muerte a un niño potencialmente recuperable.

Además, la toma de decisiones, en estas circunstancias, enfrenta diversas barreras que dificultan lograr el mejor interés del paciente. Entre ellas, los temores legales son un factor importante. ¿En qué medida esos temores están justificados?

a. Comité Hospitalario de Ética. Hospital de Pediatría SAMIC “Prof. Dr. Juan P. Garrahan".

b. Becario. Facultad de Derecho. Universidad de Buenos Aires.

Correspondencia: Dr. Jorge O. Selandari, jselandari@intramed.net

Financiamiento: El presente trabajo de investigación fue realizado con el apoyo de una beca "Ramón

Carrillo-Arturo

Oñativia", categoría perfeccionamiento, otorgada por el Ministerio de Salud de la Nación, a través de la Comisión Nacional Salud Investiga.

Conflicto de intereses:

Ninguno que declarar.

Recibido: 20-5-2015

Aceptado: 10-2-2016

\section{INTRODUCCIÓN}

El desarrollo de las ciencias médicas, en su faz tecnológica, ha determinado la aparición de tecnologías que permiten mantener la vida hasta extremos impensados no hace mucho tiempo. La necesidad de establecer un límite a esta práctica frente al ejercicio de determinados derechos (autonomía, dignidad, calidad de vida), la obligación de evitar caer en extremos dañinos (encarnizamiento terapéutico o abandono del paciente) y el rol cada vez más activo que asumen el paciente y/o sus familiares en la relación médica llevan a plantearse cómo resolver aquellos problemas sin que el paciente se perjudique y sin que el equipo de salud vea cuestionada su responsabilidad profesional. En bioética, prevalece la noción de que no todo aquello que es tecnológicamente posible de ser realizado es éticamente correcto. ¿Cuál es el enfoque que, desde el derecho penal y civil argentino, se da a estas cuestiones?, ¿está legalmente permitida la limitación del soporte vital (LSV) en pediatría? ¿Se requiere autorización judicial para la LSV en pediatría? ¿Es delito la LSV en un paciente pediátrico?

\section{OBJETIVO}

Explorar la opinión del Poder Judicial de la Nación (PJN) respecto al enfoque que, desde el derecho, se da a situaciones de LSV.

\section{POBLACIÓN}

Profesionales activos del ámbito penal, civil y médico forense. 


\section{MÉTODOS}

Estudio descriptivo transversal, cualicuantitativo, de exploración y análisis diagnóstico. La herramienta consistió en una encuesta semiestructurada, anónima, con consentimiento informado (disponible en el material suplementario on line), administrada personalmente por el becario y/o autoadministrada por el propio sujeto de investigación, con la siguiente estructura: a. Antecedentes personales y profesionales:

1. Datos demográficos.

2. Formación profesional.

3. Datos confesionales.

b. Antecedentes casuísticos y conceptuales.

c. Análisis de casos:

Para ello, la encuesta presentaba la descripción de 3 casos hipotéticos basados en situaciones que, por lo general, enfrenta el equipo de salud pediátrico, clasificados en 3 categorías comúnmente tipificadas en el análisis ético de estas situaciones. En el primer caso, un escenario de "sin posibilidades" (the no chance situation en la literatura anglosajona). El segundo, un escenario de "situación insoportable" o de extremadamente pobre calidad de vida (the unbearable situation) $\mathrm{y}$, por último, un paciente en una situación de estado vegetativo permanente. ${ }^{1}$ Se explicitaba, además, que todos los casos se desarrollaban en una situación de buena relación, entendimiento y consenso entre el equipo médico y la familia.

\section{Definición de cada categoría}

1. Situación sin posibilidades: Cuando el tratamiento simplemente retrasa la muerte, sin producir alivio significativo del sufrimiento.

2. Situación insoportable: Cuando, en una enfermedad progresiva, el tratamiento provoca solamente más sufrimiento, a pesar de la posibilidad de tener algún beneficio potencial sobre la condición subyacente.

TABLA 1. Relato de los casos hipotéticos utilizados en la encuesta

\section{Caso 1. Situación sin posibilidades}

Mariela tenía 11 años y padecía una leucemia mieloide aguda. Sometida a quimioterapia, con la finalidad de poder recibir un trasplante de médula ósea, toleró muy pobremente el tratamiento y desarrolló sepsis (infección generalizada grave) y dificultad respiratoria. Fue intubada y conectada a un respirador mecánico en Terapia Intensiva, pero su condición continuó deteriorándose y requiriendo mayores exigencias de ventilación mecánica. A pesar de la quimioterapia, la leucemia continuaba activa, lo cual, en conjunto con la circunstancia actual, configuraba una situación sin posibilidades razonables de recuperación. Los médicos y los padres acordaron no escalar más en el soporte vital (por ejemplo: asistencia respiratoria por medio de respirador artificial, diálisis o maniobras invasivas, como colocación de drenajes, etc.) y no iniciar maniobras de reanimación en caso de paro cardíaco. Mariela desarrolló falla múltiple de órganos y, cuando ocurrió el paro cardíaco, falleció sin que se intentara la reanimación cardiopulmonar.

\section{Caso 2. La situación insoportable o de muy pobre calidad de vida}

Una mamá primeriza comenzó con trabajo de parto a las 41 semanas de gestación y necesitó de una cesárea de urgencia. Tuvo un bebé de 2,700 kg, a quien llamó Ramón, relativamente pequeño para las 41 semanas. El bebé no respiró y fue resucitado, pero desarrolló convulsiones en las 4 horas posteriores. Permaneció sin respuesta y dependiendo de asistencia respiratoria mecánica (ARM) hasta los 32 días de vida. A los 45 días de vida, volvió a necesitar ARM por apneas (episodios de ausencia de respiración) y subsecuente infección respiratoria, que requirieron parámetros altos de respirador. A los 65 días de vida, presentó la primera crisis importante de broncoobstrucción con llanto y cianosis generalizada, que requirió reanimación y sedación. Estas crisis se repitieron y agravaron progresivamente a lo largo de su internación, a pesar de diversas estrategias terapéuticas, y llegó a los 9 meses de vida con requerimiento continuo de ventilación mecánica con crisis de broncoobstrucción y convulsivas que lo desestabilizaban frecuentemente, lesión neurológica extensa y grave. Toda la evidencia médica mostraba, con un alto grado de certeza, que el tiempo de sobrevida de Ramón sería con grave cuadriplejia (parálisis de los 4 miembros) y profundo déficit cognitivo. En este contexto, los médicos, enfermeros y sus padres coincidían en que las medidas de sostén vital estaban en contra del mejor interés de Ramón, en el sentido de que estas (necesidad continua de accesos intravenosos, aspiración de la vía aérea, drogas sedantes e, incluso, a veces, paralizantes) solo causaban sufrimiento adicional sin ofrecer beneficios desde el punto de vista del paciente, que solo prolongaban el sufrimiento y una vida de extremada baja calidad y que persistir en el soporte vital solo para evitar el dolor de la pérdida que sufrirían sus padres atentaba contra la propia dignidad de Ramón. Así, un día a la mañana, estando Ramón a upa de su mamá y acompañado por su papá, se lo desconectó del respirador. Las dosis de sedación se incrementaron para controlar una posible sensación de falta de aire. A los pocos minutos, Ramón hizo una apnea que desembocó en un paro cardíaco y falleció, sin intentos de reanimación.

\section{Caso 3. Estado vegetativo permanente}

Pedro, un joven de 15 años, sufrió un accidente automovilístico que le produjo un traumatismo de cráneo, que lo dejó en un estado vegetativo. Llevaba intubado y con respirador mecánico más de 17 meses y jamás había recuperado la conciencia ni expresado reacción ni interacción alguna con su mundo circundante. Sus padres solicitaron que se retirara el tubo endotraqueal y se le permitiera morir en paz. Afirmaron, desde su conocimiento de Pedro, que esta conducta era la que él hubiera querido. Los médicos retiraron el tubo endotraqueal que lo mantenía conectado al respirador artificial y Pedro murió unos 30 minutos después. 
3. Estado vegetativo permanente: condición médica que se caracteriza por la ausencia de interacción voluntaria con el medio externo, ausencia de conciencia de su mundo interior, sin posibilidades razonables de recuperación luego de 12 meses de asistencia. El paciente no experimenta dolor ni otras sensaciones conscientes, pero presenta estados de vigilia/ sueño y es capaz de hacer gestos automáticos (sonrisas, de dolor, etc.) sin una relación reconocible con los estímulos.

En la Tabla 1, se transcribe el relato de los 3 casos hipotéticos utilizados en la encuesta.

En las partes identificadas como " $\mathrm{B}$ " $\mathrm{y}$ " $\mathrm{C}$ ", se dejó un amplio margen para que el encuestado pudiera profundizar conceptos y pareceres.

El universo en estudio incluyó a todos los jueces, defensores y fiscales penales, de ambas instancias y de tribunales orales, así como los

TABla 2. Descripción de los encuestados (n: 68)

\begin{tabular}{|c|c|}
\hline Demografía & Porcentaje (n) \\
\hline $\begin{array}{l}\text { Edad mayor de } 50 \text { años, } \\
\text { Sexo masculino } \\
\text { Casados } \\
\text { Hijos }\end{array}$ & $\begin{array}{l}70 \%(35 ; 18 \text { no contestaron) } \\
73,53 \%(49 ; 1 \text { no contestó) } \\
67,31 \%(35 ; 17 \text { no contestaron) } \\
82,35 \% \text { ( } 43 ; 17 \text { no contestaron) }\end{array}$ \\
\hline $\begin{array}{l}\text { Religión } \\
\text { Católicos } \\
\text { Ateos o agnósticos } \\
\text { Judíos y otras confesiones } \\
\text { No contestaron }\end{array}$ & $\begin{array}{l}72,54 \%(37) \\
23,52 \%(12) \\
3,92 \%(2) \\
17\end{array}$ \\
\hline $\begin{array}{l}\text { Ejercicio de su religión } \\
\text { Nunca } \\
\text { Esporádicamente } \\
\text { Regularmente } \\
\text { No contestaron }\end{array}$ & $\begin{array}{l}45,8 \%(22) \\
35,4 \%(17) \\
18,8 \%(9) \\
20\end{array}$ \\
\hline $\begin{array}{l}\text { Profesión } \\
\text { Abogados } \\
\text { Médicos } \\
\text { Odontólogo/psicólogo }\end{array}$ & $\begin{array}{l}73,53 \%(50) \\
23,53 \%(16) \\
2,94 \%(2)\end{array}$ \\
\hline $\begin{array}{l}\text { Antigüedad profesional } \\
20 \text { o más años de ejercicio } \\
\text { No contestaron }\end{array}$ & $\begin{array}{l}84 \%(42) \\
18\end{array}$ \\
\hline $\begin{array}{l}\text { Cargo } \\
\text { Perito } \\
\text { Juez } \\
\text { Defensor penal } \\
\text { Fiscal } \\
\text { Defensor de menores e } \\
\text { incapaces (civil) } \\
\text { Asesor tutelar }\end{array}$ & $\begin{array}{l}26,27 \%(18) \\
48,53 \%(33) \\
17,65 \%(12) \\
1,47 \%(1)\end{array}$ \\
\hline $\begin{array}{l}\text { Formación } \\
\text { De grado } \\
\text { De posgrado } \\
\text { Doctorado }\end{array}$ & $\begin{array}{l}39,70 \%(27) \\
47,05 \%(32) \\
13,23 \%(9)\end{array}$ \\
\hline
\end{tabular}

Los porcentajes se calcularon excluyendo los ítems no contestados. defensores y asesores de menores e incapaces civiles, de ambas instancias y los médicos forenses. Se incluyó solamente al personal judicial y de la Asesoría Tutelar que, a priori, podían entender en causas de LSV en niños. Los encuestados firmaron un consentimiento informado escrito y el trabajo fue aprobado por el Comité de Ética y por el Comité de Revisión Institucional, ambos del Hospital de Pediatría "Prof. Dr. Juan P. Garrahan", y la Comisión Nacional Salud Investiga del Ministerio de Salud de la Nación.

Para la estadística descriptiva, las variables categóricas se informaron como proporciones e intervalo de confianza del 95\% (IC 95\%). El análisis univariado se realizó con la estadística de chi cuadrado. No se realizó un análisis multivariado debido al $n$ insuficiente $(n=51)$. La calificación de las respuestas fue realizada en forma independiente por los dos investigadores principales, y las diferencias, resueltas por consenso. Los datos se analizaron con el paquete estadístico Stata 9.0 para Windows (StataCorp, College Station, Texas, USA).

\section{RESULTADOS}

Entre abril y agosto de 2011, se distribuyeron 185 encuestas: 135 al PJN y 50 al Cuerpo Médico Forense. Hubo devolución en 68 (36,76\%): 50 del PJN y 18 del Cuerpo Médico Forense. De ese total, $17(25 \%)$ fueron devueltas sin responder la parte "C" de la encuesta, todas correspondientes al PJN, 7 defensores penales y 10 jueces.

En la Tabla 2, se detallan los datos descriptivos de los encuestados.

La gran mayoría de los encuestados (47: $92,15 \%)$ no intervino en ningún caso de LSV. El 96,15\% (50 sobre 52 respondidas) consideró que "causar la muerte", "ayudar a morir" y "permitir morir" no eran lo mismo.

De los 50 encuestados que respondieron sobre abstenerse de iniciar versus suspender $\mathrm{o}$ retirar un tratamiento, $84 \%$ (42) consideró que era legalmente distinto, mientras que un 16\% (8) consideró que ambas conductas eran legalmente equivalentes.

\section{Análisis de los casos hipotéticos}

Esta parte de la encuesta fue respondida por entre 48 y 51 encuestados. Diecisiete sistemáticamente no contestaron esta parte debido a la negativa de la Cámara Nacional de Apelaciones en lo Civil de permitir que los jueces del fuero civil participaran de la encuesta, al 
alegar que podrían eventualmente incurrir en prejuzgamiento si se llegara a presentar algún caso en el futuro.

En la Tabla 3, se resumen las respuestas a cada uno de los casos. De los encuestados que respondieron esta parte, el 30\% interpretaron como delito las conductas en el caso $1 ; 41 \%$, en el caso 2 ; y 39\%, en el caso 3.

En la Tabla 4, se detallan los tipos de delitos atribuidos en cada caso.

\section{Análisis conjunto de los 3 casos}

En el análisis conjunto de las respuestas de cada encuestado respecto de los 3 casos, hallamos que $28(55 \%)$ no tipificaron ningún delito en ninguno de los tres casos. Por el contrario, 13
$(25 \%)$ interpretaron como delitos las decisiones de los tres casos, $6(12 \%)$ rotularon como delito la decisión de alguno de los casos y 4 (8\%) hallaron como delito 2 de los 3 casos.

El $73,81 \%(n=110)$ de las respuestas en los tres casos acordaron la interrupción de la asistencia respiratoria mecánica (ARM). El 63,40\% (n=97) hicieron hincapié en la necesidad de que estas cuestiones fueran resueltas dentro del ámbito propio de la relación asistencial, sin recurrir a la autorización judicial. Respecto de la variación de la opinión de acuerdo con la existencia previa de una directiva médica anticipada (DMA) o de ser el paciente un adulto, en su mayoría, no modificaron su opinión -116 (76,8\%) y $115(77,2 \%)$ de las respuestas respectivas-.

TABLA 3. Respuestas de los encuestados a cada caso hipotético

\begin{tabular}{lccc}
\hline & Caso 1 n (\%)* & Caso 2 n (\%)* & Caso 3 n (\%)* \\
\hline De acuerdo, en general, con las conductas tomadas. & $45 / 51(88,23 \%)$ & $33 / 43(76,74 \%)$ & $36 / 50(72 \%)$ \\
Las conductas tomadas no configuraban delito. & $35 / 50(70 \%)$ & $29 / 49(59 \%)$ & $28 / 46(61 \%)$ \\
De acuerdo con la NO RCP. & $39 / 49(79,59 \%)$ & - & - \\
De acuerdo con retirar la ARM. & $39 / 50(78 \%)$ & $36 / 50(72 \%)$ & $35 / 49(71,42 \%)$ \\
No modificarían su respuesta aun cuando hubiera una DMA. & $40 / 51(78,43 \%)$ & $41 / 51(80,39 \%)$ & $35 / 49(71,43 \%)$ \\
No modificarían su respuesta si se tratara de un adulto. & $39 / 51(76,47 \%)$ & $41 / 50(82 \%)$ & $35 / 48(72,92 \%)$ \\
No es necesario solicitar autorización judicial para la LSV. & $35 / 51(68,63 \%)$ & $31 / 51(60,78 \%)$ & $31 / 51(60,78 \%)$ \\
No acuerda con el retiro de la hidratación o la alimentación parenteral. & - & - & $32 / 49(65,31 \%)$ \\
No acuerda con el retiro de la hidratación o la alimentación enteral. & - & - & $32 / 51(62,74 \%)$ \\
\hline
\end{tabular}

${ }^{*} \mathrm{n}=$ respuestas/respondentes que contestaron el ítem.

RCP: reanimación cardiopulmonar; ARM: asistencia respiratoria mecánica; DMA: directiva médica anticipada;

LSV: limitación del soporte vital.

TABLA 4. Tipos de delitos atribuidos en cada caso

\begin{tabular}{|c|c|c|c|c|c|c|}
\hline & \multicolumn{2}{|c|}{ Caso 1} & \multicolumn{2}{|c|}{ Caso 2} & \multicolumn{2}{|c|}{ Caso 3} \\
\hline & $\mathbf{n}$ & $\%$ & $\mathbf{n}$ & $\%$ & $\mathbf{n}$ & $\%$ \\
\hline Homicidio doloso & 4 & 8 & 11 & 23 & 9 & 19,6 \\
\hline Homicidio culposo & 5 & 10 & 3 & 6 & 4 & 8,7 \\
\hline Abandono de persona & 2 & 4 & 3 & 6 & 2 & 4,3 \\
\hline Ayuda o instigación al suicidio & 0 & 0 & 0 & 0 & 0 & 0 \\
\hline Varios delitos* & 4 & 8 & 3 & 6 & 3 & 6,5 \\
\hline Ningún delito & 35 & 70 & 29 & 59 & 28 & 61 \\
\hline Total & 50 & 100 & 49 & 100 & 46 & 100 \\
\hline
\end{tabular}

* Diversas combinaciones de los 4 delitos listados.

Tabla 5. Probabilidad de adjudicación de delito según la profesión de origen

\begin{tabular}{|c|c|c|c|c|}
\hline Origen de la profesión & Ningún caso como delito & Algún caso como delito & Total de la profesión & Tasa de "riesgo" \\
\hline Legal $^{1}$ & 15 & 20 & 35 & $57,1 \%$ \\
\hline Salud $^{2}$ & 13 & 3 & 16 & $18,7 \%$ \\
\hline Total de casos según el delito sí/no & 28 & 23 & 51 & $45,1 \%$ \\
\hline
\end{tabular}

${ }^{1}$ Abogados, que incluyen jueces, fiscales, defensores, un escribiente, etc.

${ }^{2}$ Salud, que incluye médicos, un psicólogo y un odontólogo.

Odds ratio 5,7 (IC 95\%: 1,4-24), p= 0,024 (test exacto de Fisher). 
El 47\% (n=24) de las encuestas identificaron las conductas descritas en los casos con la eutanasia. En este sentido, el caso 2 fue el que mayor porcentaje obtuvo (23\%, 11 encuestas), seguido por el caso $3(19,6 \%, 9$ encuestas). El caso 1 fue el que menor porcentaje obtuvo en esta cuestión ( $8 \%, 4$ encuestas).

No se hallaron diferencias entre opiniones tomadas por religión, sexo o entre las distintas funciones o roles (jueces, fiscales y defensores). Sí se halló una asociación significativa entre pertenecer al ámbito legal y mayor probabilidad de haber tipificado como delito alguno de los 3 casos, en comparación con los profesionales de la salud, que incluyeron médicos, un psicólogo y un odontólogo (Tabla 5). Por el contrario, no se halló que la religión (agrupada por judeo-cristiana y agnosticismoateísmo) se asociara a diferencias en la tipificación de las decisiones como delito $(p=0,9)$.

\section{Resultados cualitativos}

Los comentarios y notas que los encuestados hicieron de puño y letra más los hallazgos subjetivos que surgieron de las entrevistas personales con ellos están disponibles en el material suplementario (véase Anexo en formato electrónico).

\section{DISCUSIÓN}

La LSV es una decisión frecuente en las unidades de cuidados intensivos pediátricos (UCIP) del mundo ${ }^{2-13} \mathrm{y}$ de nuestro país, ${ }^{14} \mathrm{y}$, hasta hoy, nunca hubo un reclamo judicial en nuestro país como consecuencia de LSV.

Sin embargo, "el temor legal"* es un factor que puede afectar de modo negativo la toma de decisiones, la comunicación con la familia y la debida participación de esta en tales decisiones.

Efectivamente, el temor legal puede causar tanto encarnizamiento terapéutico ${ }^{15-20} \mathrm{como}$, en otro extremo, LSV inapropiada. ${ }^{17,18,21}$ También puede disminuir el nivel de comunicación ${ }^{22,23}$ y consulta con la familia de las decisiones de LSV.

\footnotetext{
* Entendemos el "temor legal" como el "motor" psicológico de la "medicina defensiva", término MESH y DeCS, cuya definición en primera acepción es ‘alteraciones en la forma de practicar la medicina inducida por amenazas de obligaciones y responsabilidades, con el propósito explícito de prevenir procesos judiciales por los pacientes'. (http:/ / pesquisa. bvsalud.org/portal/decs-locator/?lang=es\&tree_id=I01.88 0.604.583.524.300\&term $=\mathrm{I} 01.880 .604 .583 .524 .300$. Consulta: dic. de 2014).
}

Se podría pensar que la existencia de fundamentos bioéticos, médicos y jurídicos, y la ausencia, en nuestro país, de fallos judiciales que reprochen la LSV no justificarían esos temores. Sin embargo, este estudio explora, por primera vez en nuestro país, la opinión del mundo jurídico respecto de la LSV en niños y muestra que el temor legal del equipo de salud podría estar justificado.

Aunque, conforme lo esperado, la mayoría estuvo de acuerdo con las decisiones tomadas en los casos hipotéticos, una proporción sustancial de los encuestados (45\%) hallaron uno o más delitos en escenarios que, por presunción de los autores, describían casos ética y jurídicamente válidos de LSV y similares a los que ocurren con frecuencia en las UCIP de nuestro país. ${ }^{14,15,24,25}$

Es llamativo que operadores judiciales, más allá de su rol (juez, fiscal, defensor, asesor de menores), pudieron percibir tan disímilmente la conducta médica en su significación jurídica, tanto entre los extremos "delito-no delito" como dentro mismo de la tipificación, entre las distintas opciones presentadas (homicidio doloso o culposo, abandono del paciente, ayuda o instigación al suicidio), al punto tal de plantear, en un mismo caso, la posibilidad de tipificación de homicidio y, a su vez, la posibilidad de afirmar la inexistencia de delito. O que la misma conducta descrita pudiera tipificar cualquiera de las 4 figuras penales propuestas en forma indistinta.

Resultó evidente, durante la realización de la encuesta y de los comentarios de los encuestados, que el contacto con casos reales de la práctica pediátrica de alta complejidad en pacientes gravemente enfermos y sin posibilidades razonables de curación ni mejoría había conmovido a los operadores judiciales. En las entrevistas, se percibió la angustia que estas situaciones generaban. Se observó el esfuerzo del entrevistado de, por un lado, brindar una opinión "técnica-profesional", pero, por otro, una mirada de comprensión, empatía y compasión por el dolor ajeno. En este esfuerzo de equilibrio, cuando se opinaba técnicamente que se configuraba un delito, se intentaba "darle la vuelta" a la respuesta jurídica para buscar el encuadre jurídico que permitiera atenuar la pena, excluir la antijuridicidad o evitar la reprochabilidad.

También debe resaltarse como hallazgo positivo que muchos de los encuestados $(63,40 \%)$ hicieron hincapié en la necesidad de que estas cuestiones fueran resueltas dentro del ámbito propio de la relación asistencial y que, frente a la necesidad de intervención de un tercero distinto 
al equipo tratante y al paciente y sus familiares, proponían la actuación del Comité de Ética (CE) y evitar la judicialización de la relación asistencial.

Nosotros coincidimos con esta apreciación. Entendemos que la intervención judicial debería ser considerada como un recurso excepcional, un último mecanismo al cual recurrir cuando se han agotado todas las posibilidades de acordar con el paciente/familia el plan de tratamiento. En este sentido, el rol del CE resulta fundamental porque permite aprehender la situación de salud/enfermedad de forma holística, a través de miradas distintas, científicas y legas. Por principio, y apoyados en los hallazgos de la encuesta, el $\mathrm{CE}$ es aquel llamado a intervenir al momento de surgir discrepancias, cuestionamientos y/o dudas en torno a la adecuada toma de decisiones médicas. Solo cuando los desacuerdos conspiren contra el mejor interés del paciente, y el Comité no haya podido establecer un consenso, sería aceptable la consulta judicial.

Otro hallazgo notable es que la mayoría $(73,81 \%)$ de los encuestados en los tres casos estuvo de acuerdo con la interrupción de la ARM, situación que resulta frecuentemente problemática, ya que, aunque se acepta que el no-inicio y el retiro de soporte vital son ética y legalmente equivalentes, ${ }^{1,26-29}$ para el equipo de salud, resulta moralmente más desafiante interrumpir un tratamiento que abstenerse de iniciarlo. El profesional suele dotar de una significación psicológica/emocional distinta a la acción de abstención frente a la acción de interrupción. ${ }^{30}$ Esta última opción no suele ser aceptada con facilidad por el equipo de salud, en gran parte, porque la proximidad de la muerte del paciente a la interrupción del soporte genera una percepción de "causar" la muerte, aun cuando no sea esa la intención.

Dado lo original del trabajo, no se tienen referencias previas para comparar los resultados, pero sí existen limitaciones importantes para analizar. En primer lugar, la baja tasa de respuesta, en especial, a la parte más importante, la de los casos hipotéticos. Un $27 \%$ de tasa de respuesta de esta parte inhabilita todo intento de generalización de resultados. Sin embargo, un $45 \%$ de los encuestados opinaron que se hallaban frente a algún delito en uno, dos o todos los casos. Aún si los que no contestaron hubieran respondido que no veían delito en ningún caso, polarización de opinión altamente improbable, todavía habría un $12 \%$ de encuestados que atribuirían delito.
En segundo lugar, puede dudarse de la capacidad de la encuesta de transmitir conceptos y situaciones médicas tan complejos en forma efectiva a profesionales no médicos. Sin embargo, los encuestados se manifestaron, de manera cognitiva (no así emocional), cómodos con los relatos de la encuesta $y$, aunque era autoadministrada, el investigador estuvo a disposición para conversar y aclarar cualquier aspecto o dudas que surgieran en su lectura.

En tercer lugar, esta encuesta se realizó antes de la modificación a la Ley Nacional de Derechos del Paciente, mediáticamente denominada "ley de muerte digna" (mayo de 2012), que, sin duda, contribuyó a modificar la actitud general ante estas situaciones.

Sin embargo, existen datos que apoyan la actualidad de este tema. Por ejemplo, el caso de Marcelo Diez, un paciente adulto que permanece en estado vegetativo permanente desde hace 20 años. Sus familiares solicitaron en ámbito judicial la interrupción del soporte vital. Una pericia del Cuerpo Médico Forense Nacional y tres dictámenes de comités de bioética (Comité de la Dirección Provincial de Calidad de Gestión de la Secretaría de Salud de la Provincia de Neuquén, Comité de Ética de la Sociedad Argentina de Terapia Intensiva y Comité de Ética del INCUCAI) ${ }^{* *}$ respaldan el pedido de la familia. Actualmente, se encuentra en la Corte Suprema de Justicia, ya que, en las instancias judiciales previas, aun después de pasar por 15 miembros del PJN, que incluyen jueces de diversa instancia, procurador fiscal de la Nación, etc., y aun después de la sanción de la mencionada modificación de ley, no se otorgó el permiso para la LSV. Creemos que este tema está lejos de finalizar.

El temor legal que muchos profesionales de la salud experimentan al momento de la toma de decisiones en el final de la vida de sus pacientes podría estar justificado. Creemos que nuevas guías de práctica clínica, comprehensivas y detalladas en cuanto al proceso de toma y realización de las decisiones, tales como las publicadas en otros países, ${ }^{31-33}$ elaboradas en equipo por profesionales de la salud, la ley y bioeticistas, contribuirían a mejorar la calidad de atención de los pacientes, familiares y equipo de salud.

\footnotetext{
** Instituto Nacional Central Único Coordinador de Ablación e Implante.
} 


\section{CONCLUSIÓN}

El 45\% de los encuestados consideraron que hubo alguna forma de delito en las decisiones tomadas, y esta opinión se asoció en forma significativa con pertenecer al ámbito legal en comparación con los profesionales de la salud. Se hallaron, además, variaciones en la tipificación del delito atribuido.

\section{REFERENCIAS}

1. Royal College of Paediatrics and Child Health. Witholding or withdrawing life saving treatment in children: a framework for practice. 2nd ed. London: Royal College of Paediatrics and Child Health; 2004.Págs.10-1 y 28-9.

2. Mink RB, Pollack MM. Resuscitation and withdrawal of therapy in pediatric intensive care. Pediatrics 1992;89(5):961-3.

3. Vernon DD, Dean JM, Timmons OD, Banner W Jr, et al. Modes of death in the pediatric intensive care unit: withdrawal and limitation of supportive care. Crit Care Med 1993;21(11):1798-802.

4. Lantos JD, Berger AC,Zucker AR. Do-not-resuscitate orders in a children's hospital. Crit Care Med 1993;21(1):52-5.

5. Martinot A, Lejeune C, Beyaert C, Hue V, et al. Modes of death in a French pediatric intensive care unit (PICU). Proc Eur Soc Pediatr Intensive Care 1994;A20.

6. Burns JP, Mitchell C, Outwater KM, Geller M, et al. End-oflife care in the pediatric intensive care unit after the forgoing of life-sustaining treatment. Crit Care Med 2000;28(8):3060-6.

7. Devictor DJ, Nguyen DT. Forgoing life-sustaining treatments: how the decision is made in French pediatric intensive care units. Crit Care Med 2001;29(7):1356-9.

8. Garros D, Rosychuk RJ, Cox PN. Circumstances surrounding end of life in a pediatric intensive care unit. Pediatrics 2003;112(5):e371.

9. Devictor DJ, Nguyen DT. Forgoing life-sustaining treatments in children: a comparison between Northern and Southern European pediatric intensive care units. Pediatr Crit Care Med 2004;5(3):211-5.

10. Zawistowski CA, DeVita MA. A descriptive study of children dying in the pediatric intensive care unit after withdrawal of life sustaining treatment. Pediatr Crit Care Med 2004;5(3):216-23.

11. Kipper DJ, Piva JP, Garcia PC, Einloft PR, et al. Evolution of the medical practices and modes of death on pediatric intensive care units in southern Brazil. Pediatr Crit Care Med 2005;6(3):258-63.

12. Cuttini M, Nadai M, Kaminski M, Hansen G, et al. End-oflife decisions in neonatal intensive care: physicians' selfreported practices in seven European countries. EURONIC Study Group. Lancet 2000;355(9221):2112-8.

13. Lago PM, Devictor D, Piva JP, Bergounioux J. End-oflife care in children: the Brazilian and the international perspectives. J Pediatr (Rio J) 2007;83(2 Suppl):S109-16.

14. Althabe M,Cardigni G, Vassallo JC, Allende D, et al. Dying in the intensive care unit: collaborative multicenter study about forgoing life-sustaining treatment in Argentine pediatric intensive care units. Pediatr Crit Care Med 2003;4(2):164-9.

15. Comité de Ética Hospitalaria Hospital de Pediatría "Prof. Dr. J.P. Garrahan". Recomendaciones para la toma de decisiones terapéuticas en pacientes gravemente enfermos. Arch Argent Pediatr 1998;96(6):399-403.

16. Ballard DW, Li Y, Evans J, Ballard RA, et al. Fear of litigation may increase resuscitation of infants born near the limits of viability. J Pediatr 2002;140(6):713-8.

17. Perkins HS, Bauer RL, Hazuda HP, Schoolfield JD. Impact of legal liability, family wishes, and other "external factors" on physicians' life-support decisions. Am J Med 1990; 89(2):185-94.

18. Bell C, Somogyi-Zalud E, Masaki K, Fortaleza-Dawson T, et al. Factors associated with physician decision-making in starting tube feeding. J Palliat Med 2008;11(6):915-24.

19. Piva J, Lago P, Othero J, Garcia PC, et al. Evaluating end of life practices in ten Brazilian paediatric and adult intensive care units. J Med Ethics 2010;36(6):344-8.

20. Soares M, Terzi RG, Piva JP. End-of-life care in Brazil. Intensive Care Med 2007;33(6):1014-7.

21. Garcia-Retamero R, Galesic M. On defensive decision making: how doctors make decisions for their patients. Health Expect 2014;17(5):664-9.

22. Asher E, Greenberg-Dotan S, Halevy J, Glick S, et al. Defensive medicine in Israel. A nationwide survey. PLoS One 2012;7(8):e42613.

23. Belizan M, Meier A, Althabe F, Codazzi A, et al. Facilitators and barriers to adoption of evidence-based perinatal care in Latin American hospitals: a qualitative study. Health Educ Res 2007;22(6):839-53.

24. Ghiggi M, Chede C, Saporiti A. De lo que no se habla en la UCIP. Arch Argent Pediatr 2001;99(4):337-9.

25. Ciruzzi MS. La limitación de soporte vital: ¿Derecho, Deber o Delito? [Internet]. [Acceso: 24 de marzo de 2015]. Disponible en: http://www.unesco.org.uy/shs/ fileadmin/templates/shs/archivos/TrabajosLibresBioetica $/ 24 . \% 20 \mathrm{La} \% 201$ mitacion $\% 20 \mathrm{de} \% 20$ Soporte $\% 20$ vital.pdf.

26. Comité Nacional de Terapia Intensiva Pediátrica. Consenso sobre recomendaciones acerca de la limitación del soporte vital en terapia intensiva. Arch Argent Pediatr 1999;97(6): 411-5.

27. American Academy of Pediatrics Committee on Bioethics: Guidelines on foregoing life-sustaining medical treatment. Pediatrics 1994;93(3):532-6.

28. Monzón Marín JL, Saralegui Reta I, Abizanda i Campos $\mathrm{R}$, Cabré Pericas L, et al. Recomendaciones de tratamiento al final de la vida del paciente crítico. Med Intensiva 2008;32(3):121-33.

29. Royal Australasian College of Physicians. Decision-Making at the End of Life in Infants, Children and Adolescents. Sidney: Royal Australasian College of Physicians; 2008. [Acceso: 1 de abril de 2015]. Disponible en: https:/ / www. racp.edu.au/docs/default-source/advocacy-library / decision-making-at-the-end-of-life-in-infants-childrenand-adolescents.pdf?sfvrsn $=10$.

30. Althabe M,Ledesma F, Cernadas C, Flores C, etal. Actitudes de los profesionales de salud frente a las decisiones de limitación o retiro de tratamiento en pediatría. Arch Argent Pediatr 2003;101(2):85-92.

31. Berlinger N, Jennings B, Wolf SM. The Hastings Center Guidelines for Decisions on Life-Sustaining Treatment and Care Near the End of Life: Revised and Expanded Second Edition. New York: Oxford University Press; 2013.

32. Larcher V, Craig F, Bhogal K, Wilkinson D, et al. Making decisions to limit treatment in life-limiting and lifethreatening conditions in children: a framework for practice. Arch Dis Child 2015;100(Suppl 2):s3-23.

33. Australian and New Zealand Intensive Care Society. ANZICS Statement on Care and Decision-Making at the End of Life for the Critically Ill. Edition 1.0. Melbourne: ANZICS; 2014. 


\section{ANEXO - ANÁLISIS CUALITATIVO} Estudio descriptivo de la opinión de miembros de la justicia nacional en lo penal y civil (familia),
en situaciones de limitación de soporte vital en pediatría

\section{Comentarios y/o notas de los encuestados que respondieron haber intervenido en algún caso de limitación del soporte vital}

Juez: "No como operador jurídico. Sí a nivel personal, ocasión en la que dispuse (junto con familiares) condiciones que entendí que colaborarían con el 'buen morir' de la persona afectada".

Médico: "En Terapia Intensiva Neonatal, ante pacientes críticos (cardiopatías congénitas, sepsis, fallas ventilatorias), en los que el mantenimiento de las funciones vitales y el pronóstico se vuelven imposibles de sostener".

Médico: "Paciente con muerte encefálica con más de 78 horas; añoso, de 84 años, con falla multiorgánica como consecuencia de un accidente cerebrovascular (ACV) hemorrágico. Se suspendió el soporte".

Médico: "Autorizar la ablación multiorgánica por muerte encefálica (2 casos)".

\section{Comentarios y/o notas de los encuestados respecto de los 3 casos en general}

Jueza de Cámara. Como nota para toda la encuesta, afirmó: "Parecería contradictorio estar muy de acuerdo y al mismo tiempo considerar la conducta como delito. Legalizar la eutanasia en todas sus formas es una deuda legislativa. Instalar el tema resulta, a mi criterio, necesario. Si los médicos (generalmente, de hospitales públicos y de pacientes sin recursos) solicitan autorización para la realización de abortos terapéuticos (no punibles), más dificultades tendrían para proceder en casos como estos".

Jueza de Cámara. Se ha manifestado, en general, de acuerdo con las medidas decididas en los tres casos; como postura general del encuestado, afirmó: "Toda decisión médica vinculada a estos supuestos debe ir acompañada de un dictamen del Comité de Bioética".

Juez de instrucción. Se negó a contestar la encuesta a partir de este punto y afirmó: “El modo en que se encuentra realizada la encuesta constituye una suerte de prejuzgamiento, una emisión de opinión fuera del expediente".

\section{Caso 1. Situación sin posibilidades} Comentarios y/o notas de los encuestados al caso 1 Grado de acuerdo y presencia/ausencia de delito

Juez (que seleccionó “En general, está muy de acuerdo con las decisiones tomadas" y "Ningún delito"): "Para mí el caso es claro. Comparto la decisión de los padres y el respeto del equipo médico hacia ella. En el planteo del caso, doy por supuesto que los padres respetaron también la voluntad de la menor (11 años es una edad que permite una adecuada comunicación). Reconozco el señorío sobre el propio cuerpo. El único dato importante es qué deseaba Mariela. Falta, en nuestro país, una regulación, que, en el caso de mayores, puede concluir en un 'testamento vital"'.

Juez (que seleccionó "En general, está muy de acuerdo con las decisiones tomadas" y "Ningún delito"): "Los padres representan la voluntad del menor. Si la decisión no estuvo viciada, es absolutamente obligatoria desde el punto de vista legal, por lo que es irrelevante el punto de vista moral, que puede alegarse a favor o en contra de ella. Además, debe estar documentado debidamente".

Jueza (que seleccionó "En general, está muy de acuerdo con las decisiones tomadas" y "Ningún delito"): "El consenso de la familia y el dictamen médico fundado en la imposibilidad de sobrevida del paciente dado su estado terminal irreversible, unido a que no se realice ninguna conducta activa para producir el resultado muerte, permiten suponer que esa supuesta omisión (reanimación cardiopulmonar) no fue la consecuencia del resultado. Mi criterio, entonces, es por la última opción de esta encuesta".

Médica (que seleccionó "En general, está muy de acuerdo con las decisiones tomadas" y "Ningún delito"): "Los médicos no estamos formados para 'el buen morir' del paciente... tanto o más relevante, como el caso planteado, que el 'buen vivir'”.

Médica (que seleccionó "En general, está muy de acuerdo con las decisiones tomadas" y "Ningún delito"): "Considero que, en el ejercicio de la medicina, se debe lidiar con la omnipotencia del ser humano -el médico-, y eso incluye también considerar la opinión de la familia y trabajar en conjunto intentando siempre el 
consenso, cuidando la relación médico-paciente, y admitir los límites de la práctica. Los padres creo que son los que finalmente deberían decidir -dentro de la razonabilidad-".

Médico (que seleccionó "En general, está muy de acuerdo con las decisiones tomadas" y "Ningún delito"): "Si la situación médica que presenta el paciente es `sin posibilidades razonables de recuperación' y hay acuerdo familiar de no escalar más en el soporte vital, creo que lo más correcto es dejar que el organismo 'decida' cuál es el final y en qué momento. Lo otro es ensañamiento inhumano de vanidad médica y ¿económica?".

Médico (que seleccionó "En general, está algo de acuerdo con las decisiones tomadas" y "Homicidio culposo"): "En nuestro Código, la eutanasia está prohibida, por lo tanto, sería un delito, aunque médicamente o clínicamente quizás sería lo más conveniente".

Médico (que seleccionó "En general, está algo de acuerdo con las decisiones tomadas" y "Ningún delito"): "Imagino que, si permitieran las condiciones, se presentaría al Comité de Ética, para tener claro (independientemente del cuadro agudo y muy grave de falla multiorgánica) que no estuviese en condiciones, si hubiese superado la sepsis, de poder recibir un trasplante".

Médico (que seleccionó "En general, está muy de acuerdo con las decisiones tomadas" y "Ningún delito"): "No tenía posibilidad alguna, si el esperado trasplante era beneficioso, ¿cómo se garantizaba la carencia de secuelas? ¿Se podía asegurar una adecuada calidad de vida?".

Médico (que seleccionó "En general, está muy de acuerdo con las decisiones tomadas" y "Ningún delito"): "En estos casos, es también función del médico que el enfermo tenga un 'digno morir'. El límite del ensañamiento terapéutico es el llegar a aliviar el dolor físico. Tengo mis dudas de que la familia deba participar de esta decisión. La he tomado en soledad varias veces".

Jueza de instrucción (que seleccionó "En general, está muy de acuerdo con las decisiones tomadas" y "Ningún delito"): "Fallaría conforme las disposiciones legales y la prueba obrante en el caso concreto, constatando si realmente no existía tratamiento posible. Comprobados todos esos extremos del caso, no existiría delito".

Juez (que seleccionó “En general, está muy de acuerdo con las decisiones tomadas" y ambas opciones "Homicidio culposo" y "Ningún delito"): "Si el tratamiento omitido es el exigido como obligatorio para el caso según las reglas del arte de curar (según el protocolo médico), la omisión podría configurar una infracción al deber de cuidado médico que aumentara el riesgo de muerte (homicidio culposo podría denunciarse respecto de los médicos y padres por ser estos también garantes respecto de su hijo)".

Jueza de Cámara (que seleccionó "En general, está muy de acuerdo con las decisiones tomadas" y "Homicidio doloso"): "Si bien estoy muy de acuerdo con la decisión, como jueza, si tuviera que juzgarlo, trataría de tener en cuenta diferentes situaciones que podrían eximir de pena, pero, desde un punto estrictamente dogmático, es un homicidio doloso por omisión".

Defensor penal (que seleccionó "En general, no está de acuerdo con las decisiones tomadas" y ambas opciones "Abandono de persona" y "Ayuda e instigación al suicidio"): "Habría que ver qué pena resulta más benigna para médicos y padres".

Juez de instrucción (que seleccionó “En general, está algo de acuerdo con las decisiones tomadas" y "Homicidio doloso"): "Causa de justificación que elimine la antijuridicidad o una causa excluyente de la culpabilidad. Si bien el caso encuadra en homicidio doloso, siempre buscaría una causa de justificación o de exclusión de la culpabilidad: estado de necesidad fundado en las especialísimas circunstancias del caso".

Juez (que seleccionó "En general, está algo de acuerdo con las decisiones tomadas" y "Abandono de persona"): "Si bien podría encuadrar en el delito reprimido por el art. 106 del CP, toda vez que se está dejando a su suerte a una persona incapaz de valerse y a la que se debe mantener o cuidar, dado que el juramento hipocrático pone en tal condición al médico, ante la inminencia de una muerte inevitable, a pesar de los medios empleados, es lícito tomar la decisión de renunciar a unos tratamientos que procurarían únicamente una prolongación precaria y penosa de la existencia. Así lo estipula la Ley 17132 de Ejercicio de la Medicina en su art. 19".

Juez de instrucción (que seleccionó “En general, está muy de acuerdo con las decisiones tomadas" y "Homicidio doloso", "Homicidio culposo", "Abandono de persona" y "Ayuda e instigación al suicidio"): "Ver causas de no atribuibilidad. Están previstas en el Código: considerar el consentimiento como causa de justificación".

Juez de Cámara (que seleccionó "En general, no está de acuerdo con las decisiones tomadas" y 
"Homicidio culposo"): "Posibilidades razonables quitan sustancia a una correcta decisión jurídica en cuanto no existió posibilidad cierta de continuar con la vida. Falta de pronóstico terminal".

\section{Grado de acuerdo con la no reanimación cardiopulmonar, retiro de asistencia respiratoria mecánica}

Juez (que seleccionó "En general, está muy de acuerdo con las decisiones tomadas" y "Ningún delito"): "No modificaría su decisión si los padres la consintieran".

Juez (que seleccionó “En general, está muy de acuerdo con las decisiones tomadas", "Ningún delito" y "Sí, modificaría la decisión"): "Justamente tenía 11 años de edad, que supone madurez mínima frente a la defensa de un 'encarnizamiento terapéutico'”.

Jueza (que seleccionó “En general, está muy de acuerdo con las decisiones tomadas", "Ningún delito" y "No modificaría su decisión"): "Al menor hay que escucharlo (Convención sobre los Derechos del Niño), pero, no obstante ello, valoro el criterio de sus padres".

Médica (que seleccionó "En general, está muy de acuerdo con las decisiones tomadas", "Ningún delito" y "Sí, modificaría la decisión"): “Si no hay chance, es decir, si no hay posibilidades razonables como el caso lo plantea".

Médico (que seleccionó “En general, está muy de acuerdo con las decisiones tomadas", "Ningún delito" y "No modificaría la decisión"): “Debe respetarse la decisión del paciente aún siendo menor".

Médico (que seleccionó “En general, está muy de acuerdo con las decisiones tomadas", "Ningún delito" y "No modificaría la decisión"): “No creo poder considerar la autonomía, sobre todo con respecto a la edad".

Médico (que seleccionó "En general, está muy de acuerdo con las decisiones tomadas", "Ningún delito" y "No modificaría la decisión"): “Menores y alienados no pueden dar consentimientos válidos. No cambiaría lo que yo pienso".

* Jueza de instrucción (que seleccionó "En general, está muy de acuerdo con las decisiones tomadas", "Ningún delito" y "No modificaría la decisión"): "No modificaría mi decisión porque sigue siendo un menor de edad".

Juez (que seleccionó “En general, está muy de acuerdo con las decisiones tomadas" y "Homicidio culposo", "Ningún delito" y "No modificaría la decisión"): "No la modificaría, simplemente ponderaría el consentimiento de la víctima, la autonomía de su voluntad para disponer".

Jueza de Cámara (que seleccionó "En general, está muy de acuerdo con las decisiones tomadas", "Ningún delito" y "Sí, modificaría la decisión"): "Aunque incapaz la menor, de acuerdo con la convención y la Ley 26061, debe escuchársela".

Juez (que seleccionó "En general, está muy de acuerdo con las decisiones tomadas", "Ningún delito" y "Sí, modificaría la decisión"): “La menor tiene 11 años, lo que, en cada caso, debe evaluarse como que no tiene capacidad de comprender lo que pide o, muy por el contrario, que por ello tiene más valor".

Juez de Tribunal Oral (que seleccionó “En general, está muy de acuerdo con las decisiones tomadas", "Ningún delito" y "Sí, modificaría la decisión"): "No estoy de acuerdo con retirar u omitir nutrición/hidratación artificial porque la considero un cuidado básico y no mera terapia. El paciente menor puede adoptar sus preferencias, pero los padres deben decidir teniéndolas en cuenta".

Juez de instrucción (que seleccionó “En general, está algo de acuerdo con las decisiones tomadas", "Homicidio doloso" y "Sí, modificaría la respuesta"): "En el acto de los padres, siempre hay un componente egoísta. Si existe una voluntad documentada, es un acto de grandeza por parte de los padres".

Juez (que seleccionó “En general, está algo de acuerdo con las decisiones tomadas", "Abandono de persona" y "No modificaría la respuesta"): “En el caso de los menores, vale el consentimiento de sus progenitores o representantes, aunque puede suplirse por autorización judicial".

Juez de Cámara (que seleccionó "En general, no está de acuerdo con las decisiones tomadas", "Homicidio culposo" y "No modificaría su decisión”): “Tema capacidad jurídica”.

\section{Modificación de opinión si hay presencia de directiva médica anticipada o si es un paciente adulto}

Juez (que seleccionó “En general, está muy de acuerdo con las decisiones tomadas", "Ningún delito" y "No modificaría la decisión"): "Bajo las mismas condiciones: que la decisión no estuviera viciada y esté documentada".

Juez (que seleccionó "En general, está muy de acuerdo con las decisiones tomadas", "Ningún delito" y "Sí, modificaría la decisión"): "Siempre que la niña fuera más pequeña. Si la niña fuera 
muy pequeña o no hubiese consenso entre los tres (padre, madre, hija)".

Jueza (que seleccionó "En general, está muy de acuerdo con las decisiones tomadas", "Ningún delito" y "Sí, modificaría la decisión"): “Acá considero que la voluntad a tener una muerte digna es primordial".

Médico (que seleccionó "En general, está algo de acuerdo con las decisiones tomadas", "Ningún delito" y "Sí, modificaría su respuesta"): "Probablemente, en lo referente a las directivas anticipadas".

Médico (que seleccionó "En general, está muy de acuerdo con las decisiones tomadas", "Ningún delito" y "No modificaría la decisión"): "Un mayor hábil tiene derecho a decidir en estos casos. Confirmaría mi decisión y pensamiento al respecto".

Juez (que seleccionó "En general, está muy de acuerdo con las decisiones tomadas", "Ningún delito" y "Sí, modificaría la decisión"): "Eliminaría mis dudas sobre lo adecuado de abandonar el tratamiento".

\section{Considera necesario requerir autorización judicial}

Juez (que seleccionó “En general, está muy de acuerdo con las decisiones tomadas" y "Homicidio culposo", "Ningún delito" y "No se requiere autorización judicial"): "La ciencia médica es la idónea para diagnosticar e indicar los procedimientos necesarios para atender el caso y lo aconsejable. La intervención judicial dilataría y complicaría la cuestión, lo que agudizaría el dolor y la angustia familiar".

Jueza (que seleccionó “En general, no está de acuerdo con las decisiones tomadas", "Homicidio doloso" y "No se requiere intervención judicial"): "Los médicos están obligados a la asistencia del paciente $y$, ante la gravedad, deben prescindir del consentimiento paterno".

Juez de Tribunal Oral (que seleccionó “En general, está muy de acuerdo con las decisiones tomadas" y "Ningún delito" y "No se requiere autorización judicial"): "Considero que los comités de ética clínica institucional deben formarse para mediar entre conflictos y ofrecer recomendaciones. No son los jueces los que deben intervenir".

Defensor penal (que seleccionó "En general, no está de acuerdo con las decisiones tomadas", "Abandono de persona" y "Ayuda e instigación al suicidio" y "No se requiere intervención judicial"): "Pediría autorización judicial de necesitar. Para blindaje jurídico de los médicos y/o familiares".

Juez de instrucción (que seleccionó "En general, está algo de acuerdo con las decisiones tomadas", "Homicidio doloso" y "No se requiere intervención judicial"): "Requeriría autorización judicial a los fines de que el juez fuera un veedor de que se respetaran los derechos de todos los involucrados. Control de legalidad".

Juez (que seleccionó "En general, está algo de acuerdo con las decisiones tomadas", "Abandono de persona" y "No se requiere intervención judicial"): "Procede la autorización judicial de un juez civil únicamente si los progenitores no están de acuerdo o si hay discrepancia entre ellos, no si hay consentimiento de médicos y familiares".

Juez de instrucción (que seleccionó “En general, está algo de acuerdo con las decisiones tomadas", "Homicidio doloso" y "Sí, se requiere intervención judicial"): “Eventualmente, podría morigerarse la pena, pero no cambiaría nada con respecto a la configuración del delito".

\section{Hallazgos subjetivos}

En la apreciación individual de algunos encuestados, la expresión "situación sin posibilidades razonables de recuperación" hizo presumir que no existía la certeza suficiente para determinar la justificación de la no reanimación.

Fueron importantes los comentarios: los jueces, en general, hicieron hincapié en el respeto a la autonomía, a la voluntad del paciente y a la toma de decisiones subrogadas de los padres. Por su parte, los médicos reconocieron que no estaban formados para el buen morir y para aceptar la opinión de la familia y trabajar en conjunto. Inclusive, uno de ellos expresó "sus dudas" acerca del derecho de la familia a intervenir en la toma de decisiones y reconoció haber asumido esta responsabilidad por sí mismo, en soledad, varias veces. Otro médico, considerando el caso como eutanasia (es decir, homicidio doloso), reconoció que, desde el punto de vista médico o clínico, la decisión de limitar tratamiento sería lo más conveniente.

Cuando se les preguntó por la influencia de una directiva médica anticipada, en los comentarios, se pudo apreciar que los jueces estaban más dispuestos a aceptar la autonomía de un menor de edad y las decisiones subrogadas de los padres. No tanto así los médicos, que consideraron que menores y alienados no podían dar consentimientos válidos.

La mayoría $(76,47 \%)$ no modificaría la 
respuesta si se tratara de un paciente mayor de edad. En este punto, los jueces mantuvieron su opinión en cuanto a la validez de la toma de decisiones autónomas (fuera un paciente menor o mayor); los médicos consideraron que un paciente mayor hábil tenía derecho a decidir en estos casos.

A la luz de estos resultados, impresionó que -en el caso de los médicos- compartían las decisiones médicas asumidas en esta primera hipótesis, las que hubieran tomado independientemente de la voluntad de los padres y de la niña (porque consideraron que no podía dar un consentimiento válido). Parecería que entendieran que la propia praxis médica legitimaba la toma de decisiones con prescindencia de la intervención del paciente. También, en el caso de los médicos, se observó -en general- una confusión entre el concepto de capacidad jurídica y de competencia bioética.

\section{Caso 2. La situación insoportable o de muy pobre calidad de vida}

Comentarios y/o notas de los encuestados al caso 2 Grado de acuerdo y presencia/ausencia de delito

Jueza (que seleccionó "En general, está muy de acuerdo con las decisiones tomadas" y "Homicidio doloso"): "Las conductas pueden ser dolosas, pero estar justificadas. En el caso, debería pensarse en tratar el tema desde este estamento de la teoría del delito. En una conducta justificada, no se realiza el análisis de culpabilidad, ya que estaría permitida en nuestro ordenamiento jurídico".

Juez (que seleccionó "En general, está muy de acuerdo con las decisiones tomadas" y "Ningún delito"): "Es similar al caso anterior, la diferencia es que el menor no puede opinar. Si se concibe la muerte como un acto instantáneo, seguramente se generan opiniones adversas. Comprendiendo la muerte como un proceso irreversible, acuerdo enfáticamente con el caso".

Juez (que seleccionó "En general, no está de acuerdo con las decisiones tomadas" y "Homicidio doloso"): "El acuerdo sobre pautas morales ambiguas expresadas en términos tales como "mejor interés" o "dignidad", en el caso, no permite inferir (deducir) un consentimiento. Para que ese consentimiento tenga trascendencia jurídica, debe estar firmado, explicado y documentado debidamente. Su ausencia genera una presunción en contra del equipo médico: en el caso, la única 'decisión' fue la de no documentar 'el acuerdo', por lo que esa sería la base de análisis, ineludible para el operador jurídico. La ausencia de un acuerdo firmado habilita el inicio de la investigación penal, bajo la hipótesis de homicidio doloso".

Médica (que seleccionó "En general, está algo de acuerdo con las decisiones tomadas" y no contestó el ítem acerca de la tipificación de delito): "Si la prolongación tecnológica sostiene un final ominoso (caso 1), no tendría dudas en suspender todo soporte. Si la prolongación de la ayuda asegura sobrevida, no sería capaz, en mi condición de médica, de suspender el apoyo tecnológico sobre el niño. Supongo que me apoyaría en el Comité de Ética del hospital".

Médica (que seleccionó "En general, está muy de acuerdo con las decisiones tomadas" y "Ningún delito"): “No sostener parámetros vitales y no seguir con sufrimiento adicional para obtener como resultado un ser humano con paupérrimo desarrollo y pésima calidad de vida puede ser visto como un acto de eutanasia, en el buen sentido, de caridad si se quiere, en este caso. Igualmente, considero que la decisión final debe ser siempre consensuada con los padres y manejarse con razonabilidad, humanidad y sentido común".

Médico (que seleccionó "En general, está muy de acuerdo con las decisiones tomadas" y "Ningún delito"): "Antes de contarse con toda esta parafernalia terapéutico-instrumental improductiva (por lo menos, en los casos planteados) y cuando la muerte acontecía 'naturalmente', se pensaba que el no hacer nada era un acto delictivo. El soporte vital debe quedar restringido solo al caso que médicamente se considere favorable o de posible remisión de la causa que motiva su asistencia".

Médico (que seleccionó ambas "En general, no estar de acuerdo/estar algo de acuerdo con las decisiones tomadas" y ambos "Homicidio doloso" y "Ningún delito"): "Las decisiones deben tomarse respetando las normas vigentes, con intervención de todas las partes involucradas (padres, médicos, etc.)".

Médico (que seleccionó "En general, está muy de acuerdo con las decisiones tomadas" y "Ningún delito"): "Cuál era el beneficio buscado y el sufrimiento de la falta de aire y angustia de los padres. Ejemplo de encarnizamiento terapéutico".

Médico (que seleccionó “En general, está muy de acuerdo con las decisiones tomadas" y "Ningún delito"): "Vale aquí el mismo comentario anterior. Persistir en la terapia, en estos casos, es negarse la posibilidad de un digno morir". 
Jueza de instrucción (que seleccionó "En general, está muy de acuerdo con las decisiones tomadas" y "Ningún delito"): “Fallaría conforme las disposiciones legales y la prueba obrante en el caso concreto, constatando si realmente no existía tratamiento posible. Comprobados todos esos extremos del caso, no existiría delito".

Juez (que seleccionó "En general, está muy de acuerdo con las decisiones tomadas" y "Ningún delito"): "Igual que el primer comentario. Si el procedimiento omitido era exigible conforme el protocolo médico y necesario (habitual) para disminuir el riesgo de muerte, se podría denunciar, por homicidio culposo. En caso contrario, ningún delito, ya que no son exigibles a los médicos -de no constar en el protocoloconductas heroicas para salvar la vida, más allá de lo que ordinariamente correspondiera al caso".

Jueza de Cámara (que seleccionó "En general, está muy de acuerdo con las decisiones tomadas" y "Homicidio doloso"): "Si bien estoy muy de acuerdo con la decisión, como jueza, si tuviera que juzgarlo, trataría de tener en cuenta diferentes situaciones que podrían eximir de pena, pero, desde un punto estrictamente dogmático, es un homicidio doloso por omisión".

Jueza (que seleccionó "En general, no está de acuerdo con las decisiones tomadas" y "Homicidio doloso"): "Destaco que personalmente yo haría lo mismo, tanto si fuera padre como si fuera médico. Sin embargo, si el caso se trajera a juzgamiento, no podría soslayar que se trata de un homicidio doloso".

Defensor penal (que seleccionó "En general, no está de acuerdo con las decisiones tomadas" y "Abandono de persona" y "Ayuda e instigación al suicidio"): "Habría que ver qué pena resulta más benigna para médicos y padres".

Juez de instrucción (que seleccionó "En general, está muy de acuerdo con las decisiones tomadas" y "Homicidio doloso"): "Causa de justificación que elimine la antijuridicidad o una causa excluyente de la culpabilidad. Si bien el caso encuadra en homicidio doloso, siempre buscaría una causa de justificación o de exclusión de la culpabilidad: estado de necesidad fundado en las especialísimas circunstancias del caso".

Juez (que seleccionó "En general, está algo de acuerdo con las decisiones tomadas" y "Abandono de persona"): "Al igual que el caso anterior, si bien la conducta descrita se ajusta al tipo penal del art. 106, la Ley Nacional N. ${ }^{\circ} 17132$ estipula que, en los casos de incapacidad, los profesionales deben requerir la conformidad del representante del incapaz en cuanto sea negativa a tratarse. El principio de beneficencia que surge del juramento hipocrático se ve limitado por el principio de autonomía del paciente y prevalece, en principio, la voluntad de aquel, que posee el bien jurídico protegido. Estos principios y reglas de la bioética surgen del primer comité realizado en EE. UU. (Instituto Kennedy). Debe aclararse que, por tratarse de un menor, si bien el consentimiento de sus progenitores es fundamental, el equipo médico podría no estar de acuerdo con tal decisión y pedir una decisión judicial contraria".

Juez de instrucción (que seleccionó “En general, no está de acuerdo con las decisiones tomadas" y "Homicidio doloso"): "Agravamiento por ser los padres y atenuación por emoción violenta".

Jueza de instrucción (que seleccionó “En general, está muy de acuerdo con las decisiones tomadas" y "Homicidio doloso"): "Podría existir una atenuación: teoría del delito: disculpantes: error de prohibición o inexigibilidad de otra conducta".

Jueza de Cámara (que seleccionó "En general, está algo de acuerdo con las decisiones tomadas" y "Homicidio doloso"): "Podría llegar a ser catalogado como homicidio emocional".

Juez de instrucción (que seleccionó “En general, está muy de acuerdo con las decisiones tomadas" y "Homicidio doloso", "Homicidio culposo", "Abandono de persona", "Ayuda e instigación al suicidio"): "Técnicamente podría encuadrar".

\section{Grado de acuerdo con la no reanimación} cardiopulmonar, retiro de asistencia respiratoria mecánica y modificación de opinión si hay presencia de directiva médica anticipada

Médica (que seleccionó "En general, está muy de acuerdo con las decisiones tomadas", "Ningún delito" y "No modificaría la decisión"): “El paciente pediátrico siempre debe ser oído y debe tener la oportunidad de expresar sus opiniones al respecto, si se encuentra en condiciones de hacerlo".

Juez (que seleccionó “En general, está muy de acuerdo con las decisiones tomadas", "Ningún delito" y "Sí, modificaría la decisión"): “Igual que el comentario anterior, sumaría el consentimiento y la autonomía de la voluntad y libertad".

Jueza de Cámara (que seleccionó "En general, está muy de acuerdo con las decisiones tomadas", "Homicidio doloso" y "No modificaría la 
decisión”): “Sin legislación que la acompañe, sería más dificultoso llegar a una resolución contraria".

Juez de Tribunal Oral (que seleccionó “En general, está algo de acuerdo con las decisiones tomadas", "Ningún delito" y "Sí, modificaría la decisión"): "No estoy de acuerdo con retirar u omitir la nutrición e hidratación".

Juez de instrucción (que seleccionó “En general, está muy de acuerdo con las decisiones tomadas", "Ningún delito" y "Sí, modificaría la decisión"): "En el acto de los padres, siempre hay un componente egoísta. Si existe una voluntad documentada, es un acto de grandeza por parte de los padres".

\section{Modificación de opinión en caso de ser un paciente adulto}

Juez (que seleccionó “En general, no está de acuerdo con las decisiones tomadas" y "Homicidio doloso" y "No modificaría su respuesta"): "Con excepción de que estuvieran documentados los 'acuerdos' con el paciente acerca de lo improductivo y cruento de los tratamientos para aplicar".

Juez de Tribunal Oral (que seleccionó "Estar algo de acuerdo con las decisiones tomadas", "No tipifica delito" y "Sí, modificaría su respuesta"): "No estoy de acuerdo con retirar u omitir la nutrición e hidratación".

Defensor penal (que seleccionó "No estar de acuerdo con las decisiones tomadas", "Tipifica abandono de persona" y "Ayuda e instigación al suicidio" y "Sí, modificaría su respuesta"): "Cuando es mayor, puede disponer de su vida".

Juez (que seleccionó "Estar algo de acuerdo con las decisiones tomadas", "Tipifica abandono de persona" y "Modificaría la respuesta"): "Si se trata de un paciente mayor de edad y no deja su consentimiento por escrito, debe requerirse el de sus familiares".

\section{Considera necesario requerir autorización judicial}

Juez (que seleccionó "Estar muy de acuerdo con las decisiones tomadas", "Tipifica homicidio culposo" y "No tipifica delito" y "No se requiere autorización judicial"): "La ciencia médica es la idónea para diagnosticar e indicar los procedimientos necesarios para atender el caso y lo aconsejable. La intervención judicial dilataría y complicaría la cuestión, lo que agudizaría el dolor y angustia familiar".

Jueza de Cámara (que seleccionó "Estar muy de acuerdo con las decisiones tomadas",
"Tipifica homicidio doloso" y "El juez no puede autorizar"): "El médico debe saber el comportamiento por seguir".

Juez de Tribunal Oral (que seleccionó "Estar algo de acuerdo con las decisiones tomadas", "No tipifica delito" y "No se requiere autorización judicial"): "Recomendaría cuidados paliativos, atención a la dignidad de morir con plena asistencia afectiva, compañía comunitaria, entendimiento del sufrimiento y control efectivo del dolor".

Juez (que seleccionó "Estar algo de acuerdo con las decisiones tomadas", "No tipifica delito" y "Sí, considera pedir la autorización judicial"): "Aunque el equipo médico y familiares hubieran consentido, sería conveniente solicitar autorización judicial".

\section{Hallazgos subjetivos}

En las opiniones vertidas por profesión, los jueces, en general, hicieron hincapié en la estructura de la teoría del delito y consideraron, muchas veces, la conducta ilícita (es decir, prohibida) pero justificada (ya fuera por el consentimiento del paciente o por la indicación médica). Un juez se centró en la no documentación del acuerdo en la abstención del soporte, entre médico y familia, lo cual para él-constituía una presunción en contra del equipo tratante, lo que habilitaba la investigación judicial. Por su parte, los médicos acentuaron la pobre calidad de vida y la escasa perspectiva de mejoramiento; consideraron que el uso de la tecnología no se justificaba para prolongar el sufrimiento y destacaron que ello constituiría un encarnizamiento terapéutico.

En muchos casos, los encuestados no estuvieron de acuerdo con las medidas tomadas $(23,26 \%)$ y, aún en algunos casos en que sí estaban de acuerdo (15,52\%), consideraron que la conducta podía tipificar algún delito (homicidio doloso o culposo, en la mayoría de los casos). Esto se reflejó en algunas notas adicionales, en las cuales se consideraron posibles causas de atenuación de la pena o de justificación del delito (emoción violenta, estado de necesidad, etc.).

La expresión "solo prolongaban el sufrimiento y una vida de extremada baja calidad" generó algunas dudas entre los encuestados. Según algunos, era difícil determinar el grado de calidad y, según otros, no era razón suficiente para terminar con la vida del menor.

Informalmente, algunos jueces -durante la entrevista- interpretaron el incremento de la 
dosis de sedación como el acto final que causaba la muerte.

Si bien se reconoció la patología de base como una condición importante en el desarrollo del curso causal, quienes no estaban de acuerdo con las decisiones tomadas le asignaron a la desconexión el carácter de "causa" del fallecimiento, con todas las implicancias legales que de ello se derivan.

\section{Caso 3. Estado vegetativo permanente} Comentarios y/o notas de los encuestados al caso 3

Un juez no opinó de este caso porque le generaba dudas: "No voy a opinar sobre este caso. Me genera dudas el giro `sin posibilidades razonables de recuperación'. 'Razonable' es una convención. Por supuesto que las directivas anticipadas alterarían mi respuesta en la medida que abarcaran esta situación".

\section{Grado de acuerdo y presencia/ausencia de delito}

Jueza (que seleccionó "Estar algo de acuerdo con las decisiones tomadas" y "No tipifica delito"): "Creo que las decisiones de los padres compenetrados con la situación de salud con el ser más importante de sus vidas -un hijo- y con debido asesoramiento médico y terapéutico no pueden ni deben ser sometidas al conocimiento de los jueces".

Jueza (que seleccionó "No estar nada de acuerdo con las decisiones tomadas" y que no contestaba acerca de la tipificación del delito): "Antes de calificar la conducta de los padres, que, además de todo, sería agravada por el vínculo, con lo cual la condena sería a prisión perpetua, trataría de establecer otra cuestión por la dramática situación familiar. Pero, en este caso diferente del resto, tuve la impresión de que los que no querían seguir teniendo un hijo en esas condiciones eran sus padres. Con lo cual me aparté de las soluciones anteriores en las que no dudé. De tener que juzgar un caso así, la decisión no sería tan lineal".

Fiscal (que seleccionó "Estar algo de acuerdo con las decisiones tomadas" y que no contestaba acerca de la tipificación del delito): "Según entiendo, ha habido casos inéditos de pacientes que, habiendo estado en coma por años, han recuperado la conciencia y han podido rehabilitarse. Creo que, en estos casos, la decisión de retirar la asistencia respiratoria y otros medios artificiales de sustentación de la vida hace más al interés de la familia para evitar el sufrimiento que al propio paciente. Creo, igualmente, que, si se retira la asistencia mecánica respiratoria y el paciente muere, no configura delito. Sí en el caso de que el paciente pudiera respirar por sus propios medios y se le retirara la alimentación e hidratación".

Médica (que seleccionó "Estar muy de acuerdo con las decisiones tomadas" y "No tipifica delito"): "En este caso me parece que cuenta, aún más que en los otros, la opinión de los padres. De todas maneras, considero que son situaciones límite que es difícil ponderar desde los códigos. El cuerpo, en estas situaciones, lo pone el médico y el sufrimiento principal es de los padres. Es por ello por lo que considero que no deberían judicializarse estas situaciones, salvo que se hallen elementos de mala praxis".

Médico (que seleccionó "Estar algo de acuerdo con las decisiones tomadas" $\mathrm{y}$ "Tipifica abandono de persona"): "Es muy difícil, en este caso, el retiro del respirador. Tal vez, por edad, lo consideraría autónomo (antes del accidente) $\mathrm{y}$, en el caso de haber dejado una directiva anticipada, podría evitarse conectar al respirador si progresase, pero, necesitándolo desde el principio, me resulta muy difícil".

Médico (que seleccionó "Estar muy de acuerdo con las decisiones tomadas" y "No tipifica delito"): "Se hallaría en el denominado estado vegetativo persistente, que es uno de los cuadros clínicos en que se presenta la elección del retiro del soporte. Es razonable la decisión, más aún si se conocía la postura de Pedro en tal circunstancia".

Jueza de instrucción (que seleccionó "Estar muy de acuerdo con las decisiones tomadas" y "No tipifica delito"): "Fallaría conforme las disposiciones legales y la prueba obrante en el caso concreto, constatando si realmente no existía tratamiento posible. Comprobados todos esos extremos del caso, no existiría delito".

Juez (que seleccionó "Estar muy de acuerdo con las decisiones tomadas" y "No tipifica delito"): "Igual a los casos anteriores. En el caso, el riesgo de muerte era inevitable y el procedimiento solo dilataba el resultado; no se reprocharía porque no incrementó el riesgo ni lo provocó. Solo se adelantó y, para algunas posturas, ello no es delito".

Jueza de Cámara (que seleccionó "Estar muy de acuerdo con las decisiones tomadas" y "Tipifica homicidio doloso"): "Si bien estoy muy de acuerdo con la decisión, como jueza, si tuviera que juzgarlo, trataría de tener en cuenta diferentes situaciones que podrían eximir de pena, pero, 
desde un punto estrictamente dogmático, es un homicidio doloso por omisión".

Jueza (que seleccionó "Estar muy de acuerdo con las decisiones tomadas" y "No tipifica delito"): "Entiendo que es un caso previsto por la ley de ablaciones".

Defensor penal (que seleccionó "No estar nada de acuerdo con las decisiones tomadas" y "Tipifica abandono de persona" y "Ayuda e instigación al suicidio"): "Habría que ver qué pena resulta más benigna para médicos y padres".

Juez de instrucción (que seleccionó "Estar muy de acuerdo con las decisiones tomadas" y "Tipifica homicidio doloso"): "Causa de justificación que elimine la antijuridicidad o una causa excluyente de la culpabilidad. Si bien el caso encuadra en homicidio doloso, siempre buscaría una causa de justificación o de exclusión de la culpabilidad: estado de necesidad fundado en las especialísimas circunstancias del caso".

Juez (que seleccionó "No estar nada de acuerdo con las decisiones tomadas" $\mathrm{y}$ "Tipifica homicidio doloso"): "La eutanasia representa un derecho del paciente a decidir la forma y el momento de su muerte, pero que busca como único fin el liberar a una persona de sus intensos sufrimientos, de una agonía inmisericorde que padece como resultado de una enfermedad grave e incurable. En Argentina, no se encuentra permitida dicha conducta, contrariamente a Uruguay y Holanda, que tienen una ley al respecto. Si bien nuestros proyectos de Código Penal de 1937, 41 y 60 estimaban que debía diferenciarse, a los fines de la pena, el homicidio piadoso del común, no se decretaba la justificación de la eutanasia, puesto que el hecho seguía siendo punible, aunque distinguido por su gravedad. Por lo tanto, la conducta relatada, dada la legislación vigente, resulta punible".

Juez de instrucción (que seleccionó "No estar nada de acuerdo con las decisiones tomadas" y "Tipifica homicidio doloso"): "Agravamiento por ser los padres y atenuación por emoción violenta".

Grado de acuerdo sobre el retiro de la asistencia respiratoria mecánica, retiro de la hidratación y alimentación parenteral y/o enteral y modificación de opinión si hay presencia de directiva médica anticipada que solicite el retiro/ abstención de la asistencia respiratoria mecánica o de la hidratación y alimentación artificial

Juez (que seleccionó "Estar muy de acuerdo con las decisiones tomadas", "No tipifica delito" y "Sí, modificaría su respuesta"): "Bajo las mismas premisas del caso, es decir que los padres conocieran y asintieran ese testamento vital".

Jueza (que seleccionó "No estar nada de acuerdo con las decisiones tomadas", que no contestó sobre la tipificación del delito y que "Sí, modificaría su respuesta"): "En el caso, el adolescente tiene 15 años. Hubiera sido importante saber que él tampoco quería vivir en esas condiciones".

Médica (que seleccionó "Estar muy de acuerdo con las decisiones tomadas", "No tipifica delito" y "Sí, modificaría su respuesta"): “En d) y e), creo que la decisión depende de los padres y que los médicos deben trabajar con ellos para llegar al mejor final que se pueda, si no hay posibilidades de recuperación".

Juez (que seleccionó "Estar muy de acuerdo con las decisiones tomadas", "Tipifica homicidio culposo" y "No modificaría su respuesta"): "Sumaría el consentimiento y la autonomía de la voluntad y libertad".

Defensor público de menores e incapaces (civil) (que seleccionó "Estar algo de acuerdo con las decisiones tomadas", "No tipifica delito" y "Cambiaría de opinión"): "Partiendo del supuesto que la directiva fue emitida como menor adulto (mayores de 14 años)".

Juez de Cámara (que seleccionó "No estar nada de acuerdo con las decisiones tomadas", "Tipifica homicidio culposo" y "No modificaría la respuesta"): "Sería interesante redefinir el concepto de paciente pediátrico".

\section{Modificación de opinión en caso de ser un paciente adulto}

Médica (que seleccionó "Estar muy de acuerdo con las decisiones tomadas", "No tipifica delito" y "Sí, modificaría su respuesta"): "Seguiría las directivas que dejó el paciente".

Médico (que seleccionó "Estar muy de acuerdo con las decisiones tomadas", "No tipifica delito" y "No modificaría su respuesta"): "La medicina debe tener un criterio humanístico más que mecanicista. El importante avance tecnológico no debe desvirtuar este criterio. Debe estar al servicio de la vida y no al servicio de la muerte".

Juez de Tribunal Oral (que seleccionó "Estar muy de acuerdo con las decisiones tomadas", "No tipifica delito" y "No modificaría su respuesta"): "Recomendaría cuidados paliativos. Hasta el momento de permitir la muerte natural, se privilegia el cuidado paliativo, que incluye 
nutrición e hidratación".

Defensor penal (que seleccionó "No estar nada de acuerdo con las decisiones", "Tipifica delito de abandono de persona" y "Ayuda e instigación al suicidio" y "Modificaría su respuesta"): "Cuando es mayor, puede disponer de su vida".

Juez de instrucción (que seleccionó "No estar nada de acuerdo con las decisiones tomadas", "Tipifica homicidio doloso" y "Sí, modificaría su respuesta"): "Si fuera de edad avanzada y con DMA".

\section{Considera necesario requerir autorización judicial}

Juez (que seleccionó "Estar muy de acuerdo con las decisiones tomadas", "Tipifica homicidio culposo" y "No tipifica delito" y "No se requiere intervención judicial"): "La ciencia médica es la idónea para diagnosticar e indicar los procedimientos necesarios para atender el caso y lo aconsejable. La intervención judicial dilataría y complicaría la cuestión, lo que agudizaría el dolor y angustia familiar".

Juez (que seleccionó "Estar algo de acuerdo con las decisiones tomadas", "No tipifica delito" y "No se requiere intervención judicial"): "Según Molinario/Aguirre Obarrio, Pasteur protagonizó un hecho similar (Molinario, Los delitos, T. I, pág. 122, Ed. TEA, 1996)".

Juez (que seleccionó "No estar nada de acuerdo con las decisiones tomadas", "Tipifica homicidio doloso" y "Sí, se requiere intervención judicial"): "Resultando una conducta reprimida por la ley penal, deviene necesario solicitar autorización para el caso particular".

\section{Hallazgos subjetivos}

Entre las opiniones, resaltó la de un juez que señaló que las decisiones asistenciales debían ser tomadas dentro del marco de la relación médica y no ser sometidas al conocimiento del juez. Otro juez remarcó que se apartó de las respuestas dadas en los dos anteriores casos porque sintió que quienes no querían tener un hijo en esas condiciones eran los padres y lo vio como una conducta egoísta de ellos. Sin embargo, destacó que -en el caso de tener que juzgarla- probablemente, tendría en cuenta la situación dramática familiar. Un fiscal señaló que la limitación de soporte se debía más al interés de los padres que del propio paciente. De todas maneras, aclaró que las medidas asumidas no tipificaban delito, pero sí sería delito retirar la alimentación e hidratación en el caso de que el paciente pudiera respirar por sus propios medios. Por su parte, los médicos consideraron que este tipo de situaciones no debía judicializarse, salvo que se hallaran elementos de mala praxis. Otro destacó que se podía evitar intubar al paciente si tal hubiera sido su decisión, pero que le resultaba muy difícil retirar el respirador si lo había necesitado desde un principio.

La mayoría estaba de acuerdo con el retiro de la asistencia respiratoria mecánica $(71,42 \%)$. Sin embargo, cuando se les preguntó por el retiro de la hidratación y la alimentación, fuera esta parenteral o enteral, cambiaron los acuerdos, ya que la mayoría estaba en contra de su retiro (65,31\% para parenteral y $62,74 \%$ para enteral) y esta medida apareció como el límite entre lo aceptable y lo no aceptable respecto de la limitación de tratamiento.

Las expresiones "sin posibilidades razonables de curación" y "es capaz de hacer gestos (sonrisas, de dolor, etc.) que son automáticos, sin una relación reconocible con los estímulos" generaron algunas dudas entre los encuestados, ya que les hacían pensar que la situación no era tan irreversible porque existía una respuesta a los estímulos de parte del paciente.

Por lo general, las respuestas a las preguntas vinculadas a este caso resultaron muy parecidas al anterior cuando no se estuvo de acuerdo con las actitudes tomadas.

No obstante, en algunos supuestos $(22,22 \%)$, aun estando el encuestado muy de acuerdo con las decisiones, solo compartió la posición frente al retiro de la asistencia respiratoria mecánica, mas no de la alimentación e hidratación artificial (enteral o parenteral).

Ninguno de los encuestados tuvo respuestas diferentes en las preguntas sobre retiro de alimentación e hidratación parenteral y enteral (explicándoles aún que un caso solía ser más invasivo que el otro).

En algún supuesto, frente a la pregunta de si modificaría su respuesta en caso de ser un paciente mayor de edad, se respondió que se modificaría la respuesta si existiera una directiva médica anticipada.

\section{Hallazgos subjetivos generales}

Las mujeres encuestadas, durante las entrevistas, impresionaron mucho más sensibilizadas que los hombres, al identificar invariablemente a los sujetos hipotéticos como sus propios hijos, y trataron de encontrar alguna justificante que permitiera no responsabilizar 
legalmente ni a los médicos ni a los padres.

Quienes no estuvieron de acuerdo con las decisiones tomadas creyeron que una autorización judicial nada cambiaría, ya que esto equivaldría a pedir una "autorización para delinquir".

Informalmente, durante la entrevista, según lo conversado entre pregunta y pregunta, no solo los médicos serían imputados por el delito de que se tratara, sino también los padres, incluso en el grado de coautores, y les resultarían aplicables penas agravadas por el vínculo.

En cuanto a los roles, llamaron la atención las respuestas dadas por un defensor penal y un fiscal. El defensor no estuvo de acuerdo con las decisiones tomadas y encontró la conducta ilícita, aunque recalcó la necesidad de considerar algún tipo de atenuante o exclusión de la culpabilidad, mientras que el fiscal manifestó estar algo de acuerdo con las decisiones asumidas, al no considerar que tipificaran algún delito. Aparentemente, esto contrariaría, en cierta medida, el "rol esperado", en cuanto se presumiría que el defensor sería más proclive a compartir la conducta analizada y el fiscal, por el contrario, a asumir una postura más crítica.

Una gran parte de representantes del Poder Judicial (fueran jueces, defensores o fiscales) señalaron, sobre todo al momento de los comentarios, y aun cuando afirmaban la ilicitud de la conducta, la posibilidad de que se tratara de un tipo privilegiado (emoción violenta) o de una conducta justificada y, por ende, no antijurídica (consentimiento informado del paciente o subrogado por sus padres) o de una conducta que, aunque típica y antijurídica, no resultaba reprochable, fuera por inexigibilidad de otra conducta, por error de prohibición o por estado de necesidad disculpante. Una abrumante mayoría $(88,23 \%)$ precisó expresamente la necesidad de analizar la atenuación y/o exención de la pena.

También es destacable que la mayoría que se inclinó por considerar alguna de las conductas como delictivas $(73,91 \%)$ afirmó compartir la toma de decisiones y comprender humanamente la situación, pero, desde el punto de vista estrictamente jurídico, lo veían como una conducta ilícita.

Tanto abogados como médicos dieron importancia a la intervención de un Comité de Ética en la toma de decisiones, antes que pensar en una intervención judicial. Le asignaron un rol preponderante a este tipo de organismos en la relación asistencial. 